\title{
Development of Expert System for Material and Welding rod Selection in Robotic Welding
}

\author{
Adefemi Adeyemi Adekunle ${ }^{1}$, Samuel B. Adejuyigbe ${ }^{2}$, O.S. Ismaila ${ }^{3}$, A. T. \\ Akinwale $^{4}$ and O.R. Oyetunji \\ ${ }^{1}$ Mechanical Engineering Department, Ladoke Akintola University of Technology, Ogbomoso, Nigeria. \\ ${ }^{2}$ Mechanical/Mechatronics Department, Federal University, Oye, Ekiti, Nigeria. \\ ${ }^{3}$ MechanicalEngineering Department, Federal University of Agriculture, Abeokuta, Nigeria. \\ ${ }^{4}$ ComputerScience Department, Federal University of Agriculture, Abeokuta Nigeria.
}

\begin{abstract}
In artificial intelligence, an expert system is a computer system that emulates the decision-making ability of a human expert. Expert systems are designed to solve complex problems by reasoning about knowledge, represented primarily as if-then rules rather than through conventional procedural code Robotics welding has been used over the years in some advanced countries like Japan, USA etc to weld but there has been series of problems encountered with the usage of these processes or method. These includes the difficulty of designing suitable software that will enhance robotic welding, the cost and skill required thereby creating a barrier to its usage.

Welding operation is joining two metals together. The need arise for how to minimize or eliminate the error encountered when fatigue sets in, due to low efficiency of the local welder. CADD software for welding was developed using Microsoft visual studio package which was used to weld two mild steel plates together automatically, at the same time, it could be used for cylindrical hollow pipes.

Therefore, this research work is based on reducing or eliminating such problems by creating a mean of designing a suitable and competent software that can aid robotic welding at a lower cost and above all which can be operated by anybody without the requirement of programming knowledge or any special skill.

The result clearly shows that Robotic welding systems are able to operate continuously, provided appropriate maintenance procedures are adhered to. Continuous production line interruptions can be minimized with proper robotic system design. Robotic welding is faster, error free and uniformly welded all through like that of the CADD welding model developed.
\end{abstract}

Keywords: Computer Aided Design and Drafting, Robotic, Welding, Software, Expert System.

\section{Introduction}

Any successful decision-making is strongly dependent upon various capabilities that include the effective acquisition, storage, distribution, and sophisticated use of the knowledge of the human experts in the field. In the context of computer-aided systems for monitoring and information processing, these capabilities would be achieved through developing an Expert System.

Yang and Okrent [1991] had also said that the most successful application of Artificial Intelligence (AI) in decision making so far is the development of Decision Support System (DSS), particularly Expert System, which is a computer program that act as a 'consultant' or 'advisor' to decision makers. Expert Systems are cheaper compared to human experts in the long-term scenario; However, Expert Systems are relatively costly to develop but easy and cheap to operate. In addition, Expert Systems allow automation of many tasks that could not be effectively handled by human experts.

\section{The Knowledge-based System}

The Knowledge-based System is a system that contains a large amount of information. Expert System actually contains an expert's experience, rules for deductions and making educated guesses (called heuristics). Too often, the term "Expert-system" is used it describe both types of Systems. Expert systems are not developed for the purpose of experts, but to proliferate their knowledge and expertise throughout the addition, once an expert system is developed, it cannot create new ways to solve problems. It is up to the human experts to continually refine their knowledge and find better ways of solving problems.

The spectrum of applications of expert systems technology to industrial and commercial problems is so wide such that it defies easy characterization. The implications find their way into most areas of knowledge work. Expert systems are used to preserve knowledge and in training new employees. They are also used when expertise is scarce, expensive, or unavailable. They help under time and pressure constraints.

Today, joining metallic material using welding process is the most common method or ways of producing permanent joint for the production of machine parts, equipment and instruments. Welding is the 
process of joining metals or plastics together through the coalescences of the surface at the point of contact. Coalescence is generally produced by heat, or pressure or a combination of the two and critical is often required to attain adequate bonding and weld strength without deterioration of material properties.

Welding, as the most commonly used process for joining metals and plastic, is vital to the economy of a country because up to $50 \%$ of the gross national product is related to welding in one way or another [Cary and Helzer 1998].

\section{Software Engineering}

Software engineering (SE) is the application of a systematic, disciplined, quantifiable approach to the development, operation, and maintenance of software, and the study of these approaches; that is, the application of engineering to software. It is the application of engineering to software because it integrates significant mathematics, computer science and practices whose origins are in engineering. It is also defined as a systematic approach to the analysis, design, assessment, implementation, testing, maintenance and reengineering of software, that is, the application of engineering to software.

Software can be developed for a variety of purposes, the three most common being to meet specific needs of a specific client/business (the case with custom software), to meet a perceived need of some set of potential users (the case with commercial and open source software), or for personal use (e.g. a scientist may write software to automate a mundane task). Embedded software development, that is, the development of embedded software such as used for controlling consumer products, requires the development process to be integrated with the development of the controlled physical product. The need for better quality control of the software development process has given rise to the discipline of software engineering, which aims to apply the systematic approach exemplified in the engineering paradigm to the process of software development [Laplante, 2007].

According to Edward [2005], there are several different approaches to software development, much like the various views of political parties toward governing a country. Some take a more structured, engineeringbased approach to developing business solutions, whereas others may take a more incremental approach, where software evolves as it is developed piece-by-piece. Most methodologies share some combination of the following stages of software development:

- Market research

- Gathering requirements for the proposed business solution

- Analyzing the problem

- Devising a plan or design for the software-based solution

- Implementation (coding) of the software

- Testing the software

- Deployment

- Maintenance and bug fixing

Arc

These processes use a welding power supply to create and maintain an electric arc between an electrode and the base material to melt metals at the welding point. They can use either direct (DC) or alternating (AC) current, and consumable or non-consumable electrodes. The welding region is sometimes protected by some type of inert or semi-inert gas, known as a shielding gas, and filler material is sometimes used as well. [Gregory and Easterling 2008]

\section{Arc welding}

Arc welding is the process utilizing the concentrated heat of an electric arc to join metal by fusion of the parent metal and the addition of metal to joint usually provided by a consumable electrode. Either direct or alternating current may be used for the arc, depending upon the material to be welded and the electrode used. [Maamar, R. H et al., 2008]

\section{Metal}

A metal (from metallon, "mine, quarry, and metal") is an element, compound, or alloy that is good conductor of both electricity and heat. Metals are usually malleable and shiny, that is they reflect most of incident light. In a metal, atoms readily lose electrons to form positive ions (cations). Those ions are surrounded by de-localized electrons, which responsible for the conductivity. The solid thus produced is held by electrostatic interactions between the ions and the electron cloud, which are called metallic bonds.

Metals are sometime described as an arrangement of positive ions surrounded by a sea delocalized electrons. Metals occupy the bulk of the periodic table, while non-metallic elements can only be found on its right-hand side. A diagonal line, drawn from boron (B) to polonium (Po), separates the metals from the non- 
metals. Most elements on this line are metalloids, sometimes called semiconductors. This is because these element exhibit electrical properties common to both conductors and insulators. Element to the lower left of this division line are called metals, while elements to the upper right of the division line are called non-metals.

An alternating definition of metals refers to the band theory. If one fills the energy bands of a material with available electrons and ends up with a top band partly filled then the material is a metal .This definition opens the category for metallic polymers and other organic metals. These synthetic materials often have the characteristic silvery gray reflectivness (luster) of elemental metals. [William and Robert 2007]

\section{Artificial Intelligence}

Artificial intelligence is the study of systems that act in a way that to any observer would appear to be intelligent. It involves using methods based on the intelligent behaviour of humans and other animals to solve complex problems.

Expert System is a branch artificial intelligence, it is a system designed to model the behaviour of an expert in some field, such as medicine or geology. [Yang and Okrent 1991]

The knowledge base contains the specific domain knowledge that is used by an expert to derive conclusions from facts. In the case of a rule-based expert system, this domain knowledge is expressed in the form of a series of rules.

The explanation system provides information to the user about how the inference engine arrived at its conclusions. This can often be essential, particularly if the advice being given is of a critical nature, such as with a medical diagnosis system. If the system has used faulty reasoning to arrive at its conclusions, then the user may be able to see this by examining the data given by the explanation system.

The fact database contains the case-specific data that are to be used in a particular case to derive a conclusion. In the case of a medical expert system, this would contain information that had been obtained about the patient's condition.

The user of the expert system interfaces with it through a user interface, which provides access to the inference engine, the explanation system, and the knowledge-base editor. The inference engine is the part of the system that uses the rules and facts to derive conclusions. The inference engine will use forward chaining, backward chaining, or a combination of the two to make inferences from the data that are available to it.

The knowledge-base editor allows the user to edit the information that is contained in the knowledge base. The knowledge-base editor is not usually made available to the end user of the system but is used by the knowledge engineer or the expert to provide and update the knowledge that is contained within the system.

The design, development, and use of expert systems involve a number of people. The end-user of the system is the person who has the need for the system. In the case of a medical diagnosis system, this may be a doctor, or it may be an individual who has a complaint that they wish to diagnose. The knowledge engineer is the person who designs the rules for the system, based on either observing the expert at work or by asking the expert questions about how he or she works. The domain expert is very important to the design of an expert system. In the case of a medical diagnosis system, the expert needs to be able to explain to the knowledge engineer how he or she goes about diagnosing illnesses.

The Inference Engine, is concerned with combining together an appropriate line of reasoning which leads to solution or probable solution. It determines the solution by comparing the facts obtained from the analysis of the problems with supposed working mode of the car system. The inference engine imitates the specialist's reasoning process through the utility of a problem solving strategy. The inferences are drawn by matching the IF part of the rules with the known facts in the working memory and placing back the result to the working memory.

The inference engine design is implemented in the program using IF - THEN rules. These rules are given as algorithm using pseudo - code and flowchart design representations.

\section{Robot Welding}

Robot welding is the use of mechanized programmable tools which completely automate a welding process by performing the weld and handling the part. Robot welding is commonly used for resistance spot welding and arc welding in high production applications, such as the automotive industry. Robot arc welding has just begun growing quickly just recently, and already it commands about $20 \%$ of industrial robot applications. The major components of arc welding robots are the manipulator or the mechanical unit and the controller, which acts as the robot brain. The manipulator is what makes the robot move. [Books, 1991]

In recent years, in order to minimize labour cost and energy cost which makes the total cost in high production manufacturing, industrial welding has become increasingly more automated, most notably with the use of robots in resistance spot welding. In robotic welding, mechanized devices both hold the material and performs the weld and at first manual welding was its most common application but robotics welding increased 
in popularity as technology advanced. The need for robotics welding arises when high production is necessary and high quality of welded joint [Pires et al., 2002].

\section{Current Problems}

\section{Labour Cost}

Major software for Robots are not user's friendly because one might needs to be a programmer before one can operate or make use of robot to weld. The software developed is user's friendly, once one can input the parameters, the software will send the signal to the robot for actions, and easily affordable. [Adekunle et al 2012]

On the other hand, manual welding is cost effective compare to the robotic welding. Cost of maintenance of robots is so exorbitant to the extent that ordinary person cannot afford it [Adekunle and Adejuyigbe 2012].

\section{Type of Welded Joint}

Currently, one will need to use software for a particular mode of welding. If one is changing the welding type, there would be need to change the software to accommodate that, but the software developed will work for all types of welding e;g, Butt welding, Overlap welding, T-Joint, etc.

Whenever robotic arc welding operation is taking place, there is no way one will not be moving the materials to be welded to a welding spot either by pushing or pulling, in other for the operation to commence. The generated software is so developed to push the materials to each other for the commencement of welding operation

\section{Types of welding rods}

When welding operation is about to take place, the operator will have to decide what type of welding rod is to be used. This might call for expertness in decision making, but the software developed has taken care of that in the sense that the welding rod that goes with the material chosen to be welded will be highlighted.

\section{Microsoft Visual Studio}

\section{Materials And Method}

This is an integrated development environment (IDE) from Microsoft. It is used to develop console and graphical user interface application along with window forms application, website, web applications and web services in both native code together with managed code for all platforms supported by Microsoft windows, windows mobile, windows CE, .NET framework, .Net compact framework and Microsoft silver light.

Visual studio includes a code editor supporting intelligence as well as code refractory. The integrated debugger works both as a source lead debugger and a machine level debugger. Other built in tools include a forms of designer for building GUI applications, web designer, class designer and data base schemer designer. It accepts plug in that enhance the functionality at almost every level including adding support for source control systems(like sub version and visual source safe) and adding new tool sets like editors and visual designers for domain. Specific languages or tool sets for other aspect of the software development life cycle (like the team foundation server client: team explorer)

Visual studio supports different programming languages by means of language services, which allow the code editor and debugger to support (to varying degrees) nearly any programming language, provided a language specific exist. Built in languages include $\mathrm{C} / \mathrm{C}++$ (via visual $\mathrm{C}++$ ), VB.NET (via visual basic.NET), $\mathrm{C} \#$ (visual $\mathrm{CH}$ ) and $\mathrm{F} \#$ (as of visual studio).

Visual studio includes a host of visual designers to aid in the development of applications or software. These tools include:

\section{Microsoft Visual C\#}

This is the Microsoft implementation of the $\mathrm{C \#}$ specification included in the Microsoft Visual studio suite of products. It is based on the ECMA or ISO specification of the $\mathrm{C \#}$ language which Microsoft also created. While multiple implementations of the specification exist, visual C\# is by far the one most commonly used.

\section{Results}

Robot is used mainly because of its flexibility, but also because they can perform very precisely human like tasks. And welding is indubitably a human like task requiring precise motions. Robots are essentially position-controlled devices that can receive a trajectory and run it continuously.

The software used consisted of the Microsoft Visual studio package and Microsoft C\# language. The main reason for using Microsoft Visual studio was for its world-wide use, easy interface, being an open system 
and its ease of file formats acceptability. Three Dimensions solids were used as well as surfaces. Microsoft Visual studio has its own programming language which makes it possible to customize programs according to specific application needs.

As with any complex technological process, control a welding robotic process and monitor its quality means acting on the two phases of the process (before, in between and after):

\section{Sequence Of Welding Operation Captured}

After the CADD software had been developed, it was used to simulate welding operation, and these were captured sequentially.
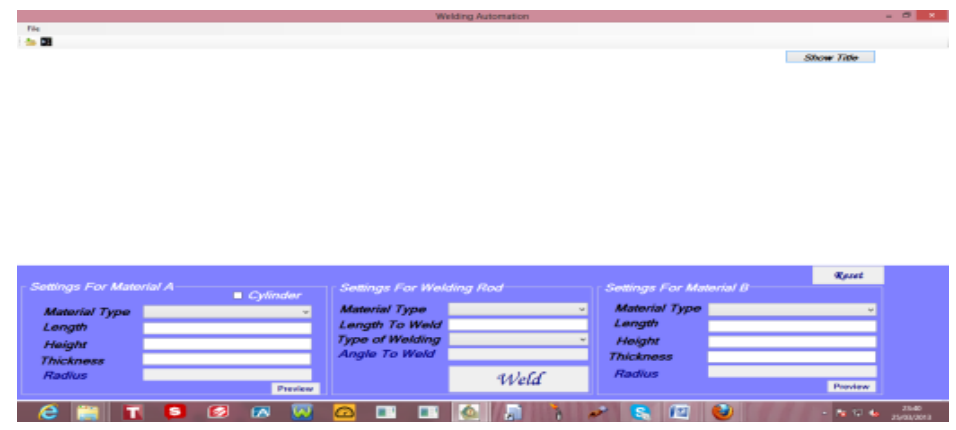

Fig. 1: Interface for plate material

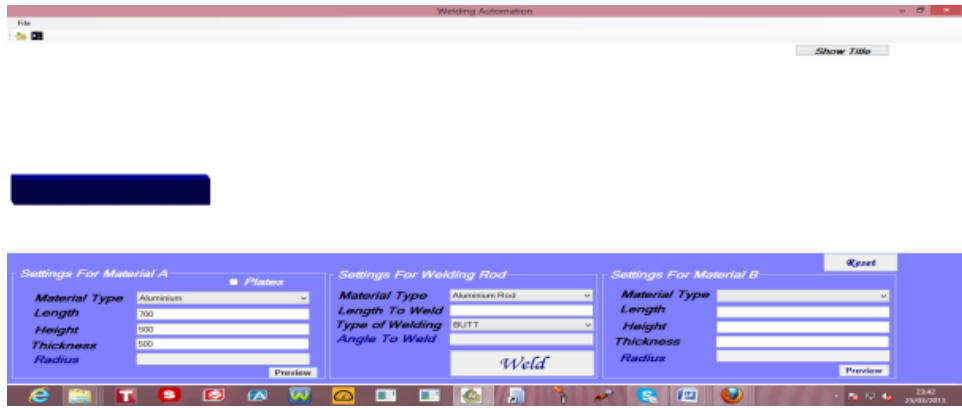

Fig. 2: Setting for material $A$

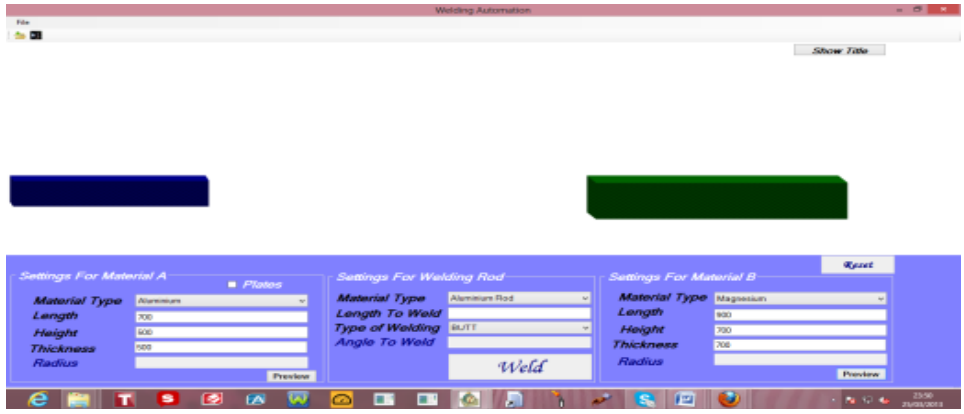

Fig. 3: Setting for material B

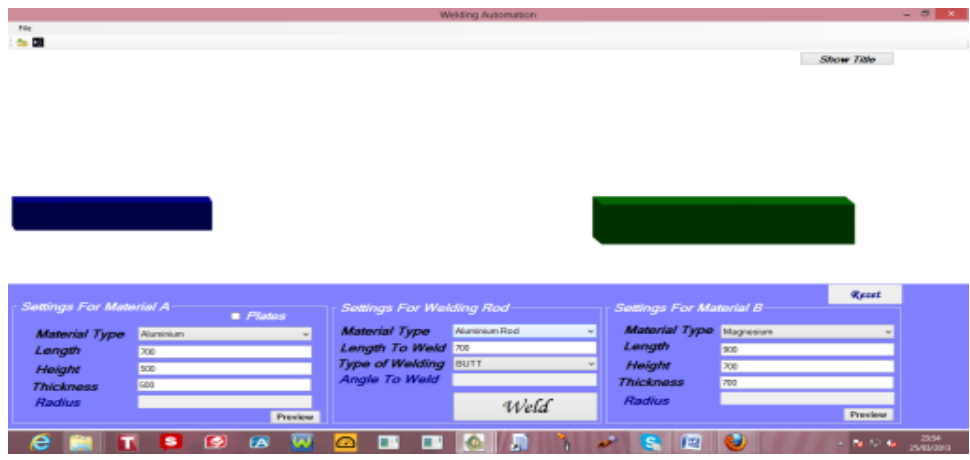

Fig. 4: Setting for welding rod 


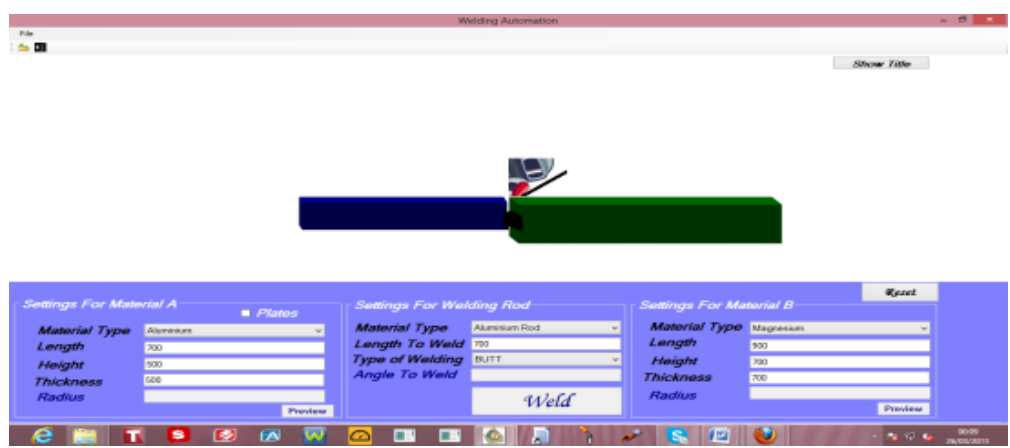

Fig. 5: welding operation captured

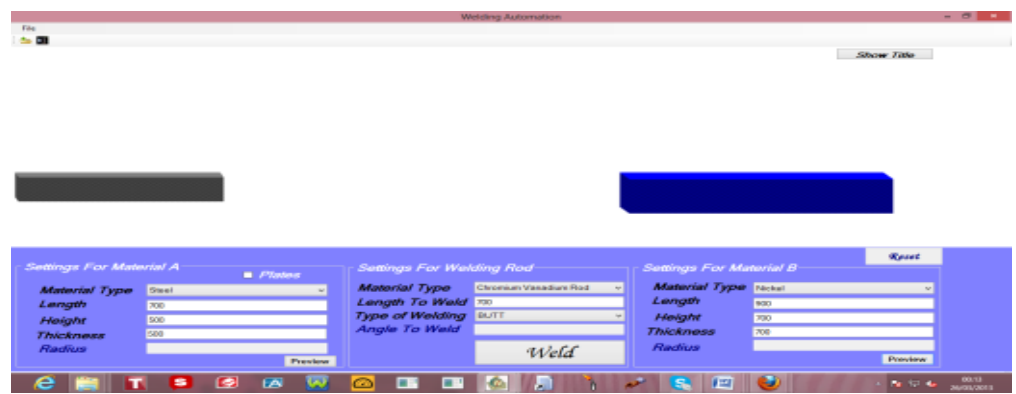

Fig. 6: Steel and Nickel selected

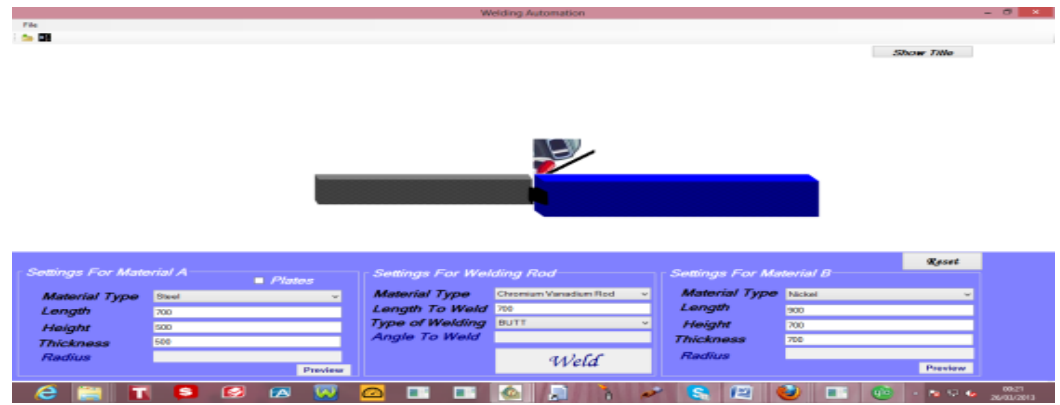

Fig. 7: welding operation captured

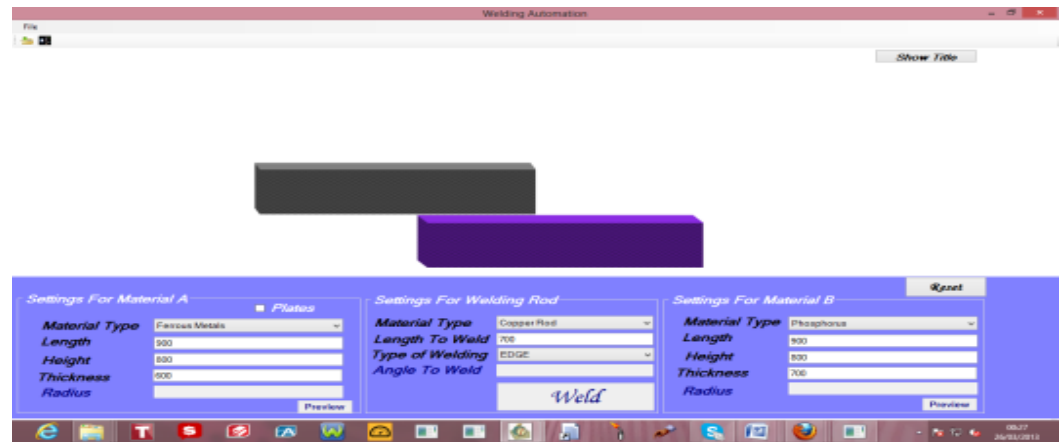

Fig. 8: materials selected

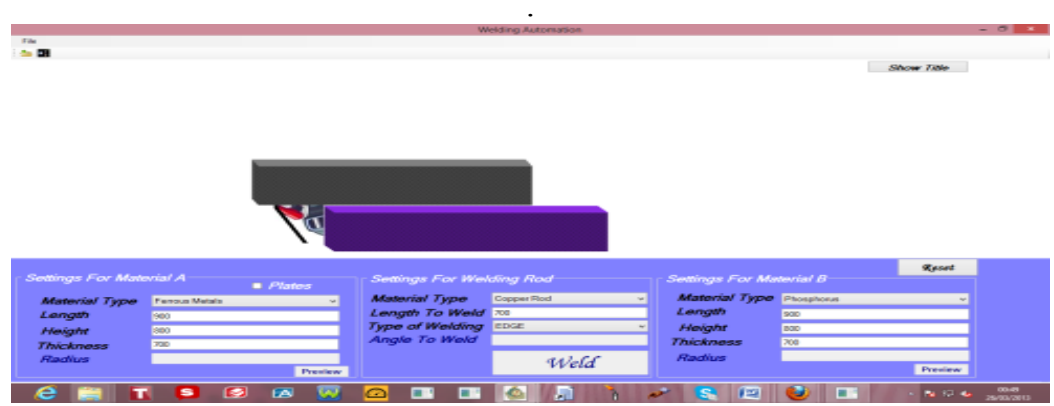

Fig. 9: Aluminium and Magnesium

www.iosrjournals.org 


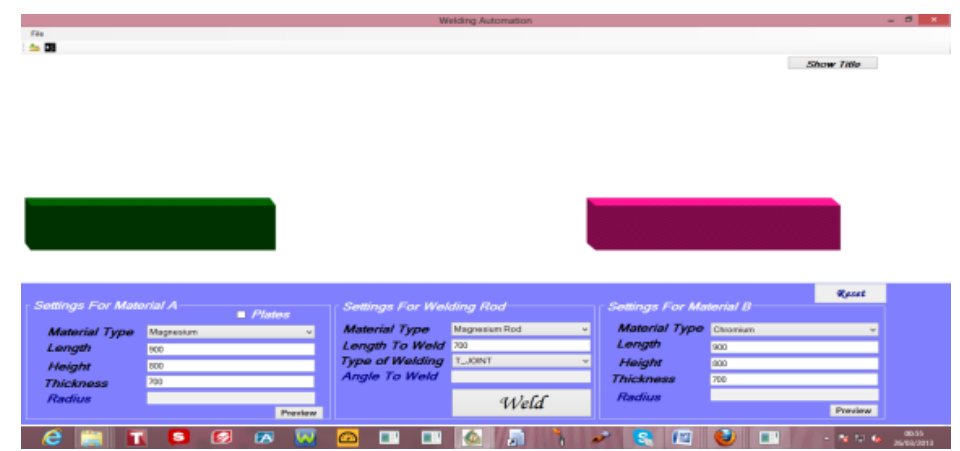

Fig. 10 Magnesium and Chromium selected

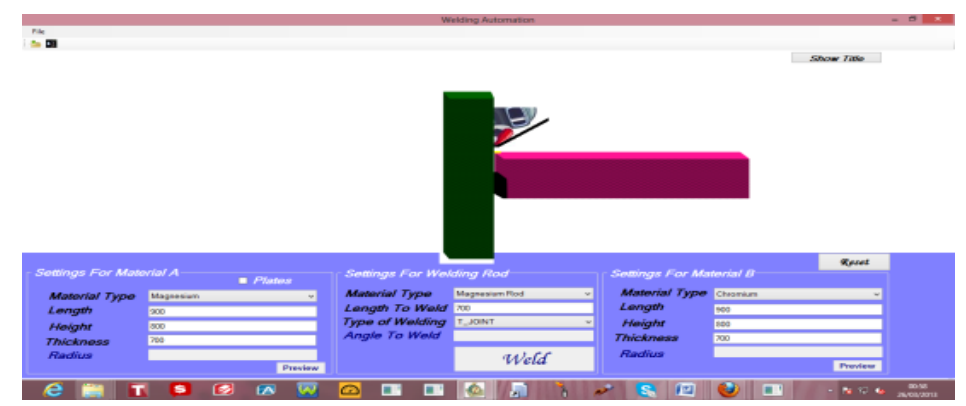

Fig. 11: Magnesium and Chromium

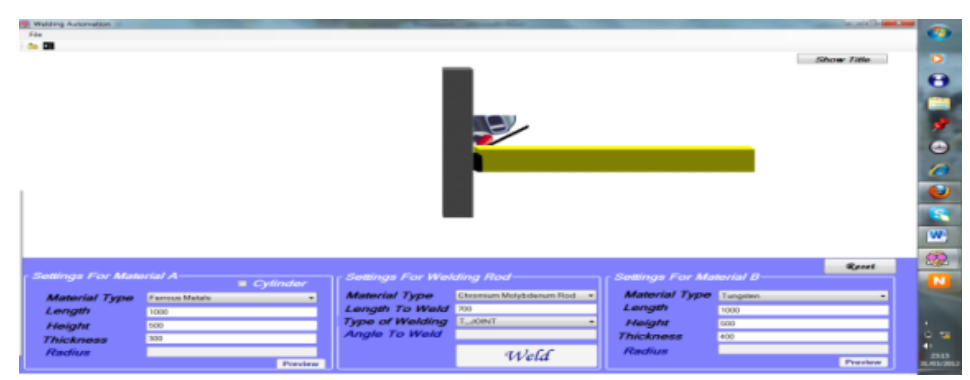

Fig. 12: T- Joint type of welding

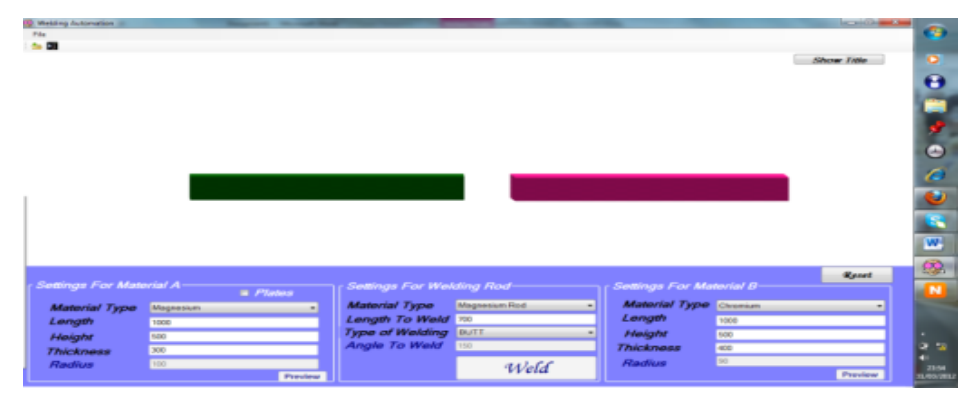

Fig. 13: Magnesium and Chromium

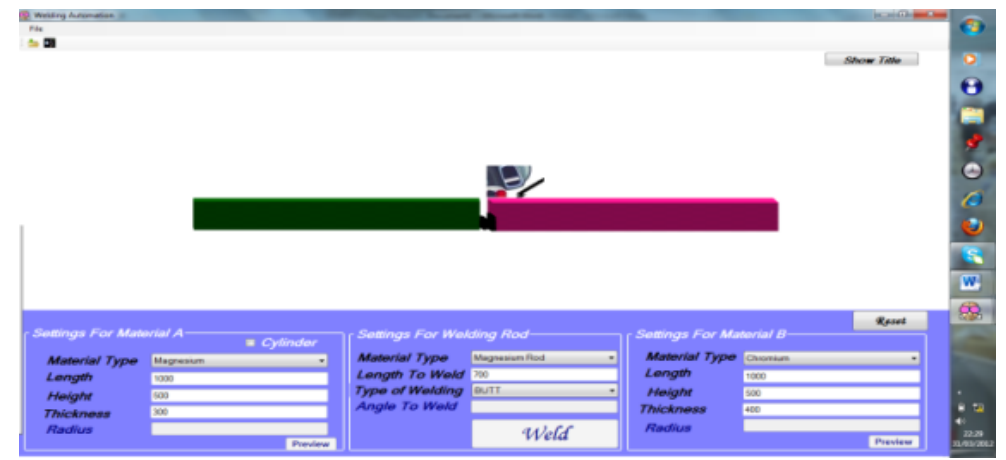

Fig. 14: Butt welded type of joint 


\section{Discussons}

Figure 1: This is where the settings for the parent material, i.e material A, settings for welding rod, and settings for material B were input.

Figure 2: Aluminium was chosen as material A in the settings, Length, Height and Thickness of the material was input as $700 \mathrm{~mm}, 500 \mathrm{~mm}$ and $500 \mathrm{~mm}$ as shown in figure 2

Figure 3: Magnesium was chosen as material $B$ in the settings, Length, Height and Thickness of the material was input as $900 \mathrm{~mm}, 700 \mathrm{~mm}$ and $700 \mathrm{~mm}$ as shown in figure 3

Figure 4: Aluminium rod was chosen for welding rod, length of weld input was $700 \mathrm{~mm}$, and Butt weld was selected as welding type

Figure 5: When the two materials got closer together, clicking the weld button automatically starts welding operation. Under the settings for welding rod, Butt welding was chosen for welding type.

Figure 6: Steel was selected for material A, and Nickel was selected for material B. The colour codes depicted the material selection; chromium Vanadium welding rod was selected.

The figure 7: It shows the welding operation of Steel and Nickel in operation.

Figure 8: Welding rod material was selected, and the input parameter was specified

Figure 9: Material "A" made of Aluminium and material "B" which is made of Magnesium were detected by the software, and the colour code was designed to designate each material.

Figure 10: Welding operation in progress for Butt welded joint for Aluminium and Magnesium

Figure 11: Magnesium and Chromium selected as welding materia, and Tee welded joint selcted. The software brought the materials together for welding to take place.

Figure 12: Welding operation of the materials in progress for T- Joint type of welding

Figure 13: Magnesium and Chromium materials were selected for welding, the software then selected Butt welded type of joint.

Figure 14: Welding operation in progress for Magnesium and Chromium materials

\section{Conclusions}

In this research work, we developed a CAD software for welding that is very easy to simulate and adjust. The software is capable of selecting the type of materials to be welded, for instance, material "A" made of Aluminium and material " $\mathrm{B}$ " which is made of Magnesium was detected by the software, and the colour code was designed to designate each material. The system was tested using different specifications supplied and showed to be accurate and very easy to use. The Expert system is capable of selecting a welding rod that best fits the welding operation selected, and the type of welding joint needed for the welding operation. One good thing about the software is that it can be used for welding both plate and cylindrical material sequentially.

\section{References}

[1] Cary, H.B.; Helzer, S.C. (1998) Modern Welding Technology, 6th ed.; Prentice Hall: Upper Saddle River, NJ, USA, pp. 1-2.

[2] Laplante, Phillip (2007). What Every Engineer Should Know about Software Engineering. Boca Raton: CRC

[3] Edward Hasted (2005). Software That Sells: A Practical Guide to Developing and Marketing Your Software Project.

[4] Gregory L. Snow and W. Samuel Easterling (2008) "Strength of Arc Spot Welds Made in Single and Multiple Steel Sheets", Proceedings of the 19th International Specialty Conference on Cold-Formed Steel Structures, Missouri University of Science and Technology, October 2008

[5] Maamar, R. H., Otmani, T. R., and Fahssi, N. D. D., (2008). Heat Treatment and Welding Effects on Mechanical Properties and Microstructure Evolution of 2024 and 7075 Aluminium Alloys. Centre de Recherche Scientifique et Technique en Soudage et Contrôle. Division de Mécanique et Métallurgie, Algeria. Vol. 5, pp. 13. - 15.

[6] William, F. Hosford and Robert M. Caddell (2007). Metal Forming: Mechanics and Metallurgy. Cambridge University Press, New York Third Edition, pp. 30-32.

[7] Books B. (1991)."Welding Robots - The State of the Art", Welding and Metal Fabrication

[8] Pires J.N., Loureiro A., Godinho T., Ferreira P., Fernando B. and Morgado J. (2002).”Object Oriented and Distributed Software Applied to Industrial Robotic Welding", Industrial Robot: An International Journal, Vol. 29 No. 2, pp. 149-162

[9] Adekunle A.A. and Adejuyigbe S. B. (2012) Computer Aided Design and Drafting (CADD) Modeling for Gas Welding Process. $J$ Am Sci 2012;8(7):87-93]. (ISSN: 1545-1003). http://www.jofamericanscience.org.

[10] Adekunle A.A., Adejuyigbe S. B and Arulogun O.T. (2012). Computer Aided Design and Drafting Software development for Robotic Welding "Proc. of Int. Conf. on Mechanical Engineering and Mechatronics" Ottawa, Canada Aug. 15-17, pp. 38-1962-381983 